\title{
Frontiers in air quality modelling
}

\author{
A. Colette, B. Bessagnet, F. Meleux, E. Terrenoire, and L. Rouil \\ Institut National de l'Environnement Industriel et des Risques (INERIS), Verneuil-en-Halatte, France
}

Correspondence to: A. Colette (augustin.colette@ineris.fr)

Received: 8 July 2013 - Published in Geosci. Model Dev. Discuss.: 2 August 2013

Revised: 8 December 2013 - Accepted: 17 December 2013 - Published: 28 January 2014

\begin{abstract}
The first pan-European kilometre-scale atmospheric chemistry simulation is introduced. The continentalscale air pollution episode of January 2009 is modelled with the CHIMERE offline chemistry transport model with a massive grid of 2 million horizontal points, performed on 2000 CPU of a high-performance computing system hosted by the Research and Technology Computing Center at the French Alternative Energies and Atomic Energy Commission (CCRT/CEA). Besides the technical challenge, we find that model biases are significantly reduced, especially over urban areas. The high-resolution grid also allows revisiting of the contribution of individual city plumes to the European burden of pollution, providing new insights to target the appropriate geographical level of action when designing air pollution mitigation strategies.
\end{abstract}

\section{Introduction}

Beside the challenges in understanding and representing physical and chemical processes, the most common limitation mentioned in geophysical modelling studies regards spatial resolution, often restricted because of computational cost. With the ever growing computing facilities, such limitations are systematically pushed back and we are now able to introduce a continental scale atmospheric chemistry simulation with the CHIMERE model at 2-km resolution, whereas such high spatial resolutions are limited to local air quality models (for a comprehensive review see Zhang et al., 2012; and references therein). Capturing small-scale air pollution features over such a large domain at a glance will allow (1) comparing of local air quality throughout the continent based on homogenous input data, (2) improving of model performance in terms of scores, exceedances, and exposure over a large domain, (3) better represent pollution transport from sources to remote areas and therefore revisit the assessment of the respective role of local sources versus regional background of air pollution. This paper puts into perspective this achievement with the current state of the art in regional atmospheric chemistry modelling. We highlight the strength and weaknesses of the simulation and discuss the relevance of very high performance computing in the field of environmental modelling.

One of the main air pollution outbreaks in Europe in 2009 occurred between 9 and 16 January with particulate matter (fine, less than $2.5 \mu \mathrm{m}$ and coarse, less than $10 \mu \mathrm{m}$, i.e. $\mathrm{PM}_{2.5}$ and $\left.\mathrm{PM}_{10}\right)$ and nitrogen dioxide $\left(\mathrm{NO}_{2}\right)$ levels reaching alert levels (MEEDDM, 2010; Chiappini, 2009; Favez et al., 2010) in various places. The main driving factor for this event was an intense cold spell (DWD, 2010) that led to high anthropogenic emissions of pollutants from domestic heating and a stable meteorological situation enhancing the accumulation of air pollution in the thin planetary boundary layer. While Western Europe was exposed to high levels of pollution at the beginning of the period, the pollution plume moved eastwards towards the end of the period as a result of the displacement of the cold spell and the advection of Western pollution. The conjunction of long-range transport and contribution of local sources supports the relevance of this event to investigate the added value of highresolution continental-scale atmospheric chemistry simulations. The choice of a wintertime event to assess the added value of spatial resolution is further supported by the findings of Fountoukis et al. (2013), who, by comparing 36 and $4 \mathrm{~km}$ simulations over the Paris area, demonstrated the lower sensitivity in summer, when the formation of secondary organic aerosols smear out the spatial variability.

The horizontal resolution in the simulation used here is about $2 \mathrm{~km}$, the lower limit being set by the availability of proxy data in building the emission inventories rather 
than computational capacities or cost. With such a resolution, the European continent is covered with slightly more than 2 million horizontal grid cells. These numbers should be put into perspective with current practices in air pollution forecasting, where a resolution of about $10 \mathrm{~km}$ is achieved by the Modelling Atmospheric Composition Change (MACC) project of the Global Monitoring for Environment and Security programme of the European Commission (www.gmes-atmosphere.eu, Zyryanov et al., 2011) and the US air quality forecasting system of the National Oceanic and Atmospheric Administration and Environmental Protection Agency (Eder et al., 2009). The factor 5 between MACC forecasts $(\sim 10 \mathrm{~km})$ and the present work $(\sim 2 \mathrm{~km})$ leads to a computational demand two orders of magnitude $(5 \times 5$ for the number of horizontal points, and another factor 5 for the increment in the time step) above current practices. Such a change in the order of magnitude of the spatial refinement of the European air quality model can however only be achieved over a limited period of time and we will focus here on a single air pollution event rather than an annual simulation, as would be common practice in regular air quality model evaluation studies.

Section 2 presents the details of the methods in summarizing the setup of the CHIMERE chemistry transport model and highlighting the main features of input data (especially high-resolution emissions). Section 3 is devoted to the analysis of the results in terms of model validation, exceedances, exposure modelling as well as pollution budgets and fluxes.

\section{Methods}

\subsection{Chemistry transport model}

The CHIMERE offline chemistry transport model (CTM) (Menut et al., 2013) was used to model the transport and transformation of trace species in the lower troposphere. The model is being used by several international teams for research and environmental policy underpinning. It has been involved in a number of model inter-comparison initiatives (Colette et al., 2011; Cuvelier et al., 2007; van Loon et al., 2007; Vautard et al., 2009; Galmarini et al., 2012) and is now part of the MACC European pre-operational air composition forecasting system (Zyryanov et al., 2012) within the Copernicus programme. The model and further documentation can be found at www.lmd.polytechnique.fr/chimere. The version used here is CHIMERE-2008 (Bessagnet et al., 2008).

\subsection{Model setup}

Three spatial resolutions will be used in the present study. Apart from geometrical difference, and the related increment in time step (in order to comply with the Courant-FriedrichLevy criterion), the model setup is identical for all simulations.
The coarser domain has a resolution of 0.875 and 0.4375 degrees of longitude and latitude (i.e. approximately $57 \mathrm{~km}$ ). Global chemical fields from a 6-year reanalysis with the LMDz4-INCA3 model (Folberth et al., 2006; Hauglustaine et al., 2004) are used as boundary conditions for the coarse domain. The coarse simulation is then used as boundary conditions for two finer resolution simulations: 0.125 and 0.0625 degrees (i.e. approximately $8 \mathrm{~km}$ at the centre of the domain), and ultimately 0.03125 and 0.015625 degrees (i.e. approximately $2 \mathrm{~km}$ ). The geographical domain is identical for the two fine resolutions; it extends from $10.4375^{\circ} \mathrm{W}$ to $30.43750^{\circ} \mathrm{E}$ and from $35.906250^{\circ} \mathrm{S}$ to $61.84375^{\circ} \mathrm{N}$, while the coarse domain is $13.43750^{\circ} \mathrm{W}$ to $32.93750^{\circ} \mathrm{E}$ and $34.40625^{\circ} \mathrm{S}$ to $62.84375^{\circ} \mathrm{N}$. (see full model domains in Fig. 2). The vertical discretisation is identical for all three simulations; it has 9 layers extending from approximately $997 \mathrm{hPa}$ to $500 \mathrm{hPa}$.

The $57 \mathrm{~km}$ and $8 \mathrm{~km}$ resolution simulations include a one month spin up before 8 January 2009. At that date, the $2 \mathrm{~km}$ simulation starts using initial conditions of the $8 \mathrm{~km}$ simulation so that only 8 January 2009 is considered as a spin up for the very high-resolution simulation and discarded from the quantitative analysis below. The temporal increment of the $2 \mathrm{~km}$ simulation is $140 \mathrm{~s}$ for the physical integration and $20 \mathrm{~s}$ for the chemical solver. The simulation covers 9 days (8 January 2009 to 16 January 2009).

The main user-dependent physical and chemical parameterisation is summarized here, but the reader is referred to Menut et al. (2013) for details on the corresponding model components and references as well as non user-specific model characteristics. The gas-phase chemical mechanism is MELCHIOR2, which consists of a simplified version (40 species and 120 reactions) of the full chemical mechanism based on the concept of chemical operators. Modelled particulate matter includes primary particulate matter, and secondary inorganic (nitrate, sulphate, ammonium based on the ISORROPIA thermodynamic equilibrium model) and organic aerosol (whose formation is represented according to a single-step oxidation of the relevant anthropogenic and biogenic precursors and gas-particle partitioning of the condensable oxidation products). Biogenic emissions are computed with MEGAN version 2.04, sea-salt and desert dust are taken into account, but non-African mineral dust is excluded. Horizontal transport is solved with the second-order Van Leer scheme. Subgridscale convective fluxes are accounted for. The present setup also benefits from an improved representation of turbulent mixing in urban areas that yields lower horizontal wind and vertical mixing in order to better capture the difference between the urban canopy (where the first CHIMERE model level lies) and the top of the urban sublayer (of which the lowermost meteorological model level is representative) as described in Terrenoire et al. (2013). 


\subsection{Input data: meteorology}

As an offline CTM, CHIMERE requires prescribed meteorological fields which were provided here by ECMWF with the IFS model at $16 \mathrm{~km}$ resolution with data assimilation. The same fields are interpolated linearly at 57,8 , and $2 \mathrm{~km}$ to drive the relevant resolution CTM simulations. Unfortunately, performing a continental-scale high-resolution meteorological simulation including urban island effects is a challenge in itself and was ruled out of the present initiative, so that the resolution of the meteorological model does not match that of the CTM. It should be noted however that the added value of resolution in meteorological forcing is expected to be negligible compared with that of emission and chemistry transport (Valari and Menut, 2008).

\subsection{Input data: emissions}

The efforts of the CHIMERE development team for the present initiative were focused on the improvement of the anthropogenic emissions module (Menut et al., 2012). A few years ago, frontiers in atmospheric chemistry simulation were set by the resolution of emission inventories that were delivered at approximately $50 \mathrm{~km}$ at continental scale, whereas higher resolution (up to $1 \mathrm{~km}$ ) could only be reached over a restricted area with bottom-up inventories. However, because of heterogeneities in the input data used in bottomup emission data sets and lack of required information at the local scale, such an approach cannot yet be contemplated at continental scale. Instead, we used a top-down approach, i.e. downscaling techniques to disaggregate coarse inventories using proxies such as point source location and highresolution population density map. Here the resolution limitation is thus prescribed by the proxy data: in our case the population density map that was made available at a resolution of about $1 \mathrm{~km}$ by the Joint Research Centre of the European Commission.

More specifically, the anthropogenic emission used here is the inventory developed by INERIS in the framework of the EC4MACS project (European Consortium for Modelling of Air Pollution and Climate Strategies, http://www.ec4macs. $\mathrm{eu} /$ ). It is described in further detail in Bessagnet et al. (2012) and Terrenoire et al. (2013) and consists of an optimal combination of various sources.

National annual (2009) emission totals for each activity sector are the same as used in EMEP models provided at $0.5 \times 0.5$ degree resolution (Vestreng et al., 2007). For primary $\mathrm{PM}_{2.5}$, however, GAINS (Amann et al., 2011) national emissions totals were considered more reliable (Z. Klimont, personal communication, 2011) for the following countries: CZ, BA, BE, BY, ES, FR, HR, IE, LT, LU, MD, MK, NL, $\mathrm{CS}$, and TR.

This hybrid of EMEP and GAINS national and annual totals is then spatialised following various proxies. The basic spatial distribution follows the TNO-MACC inventory
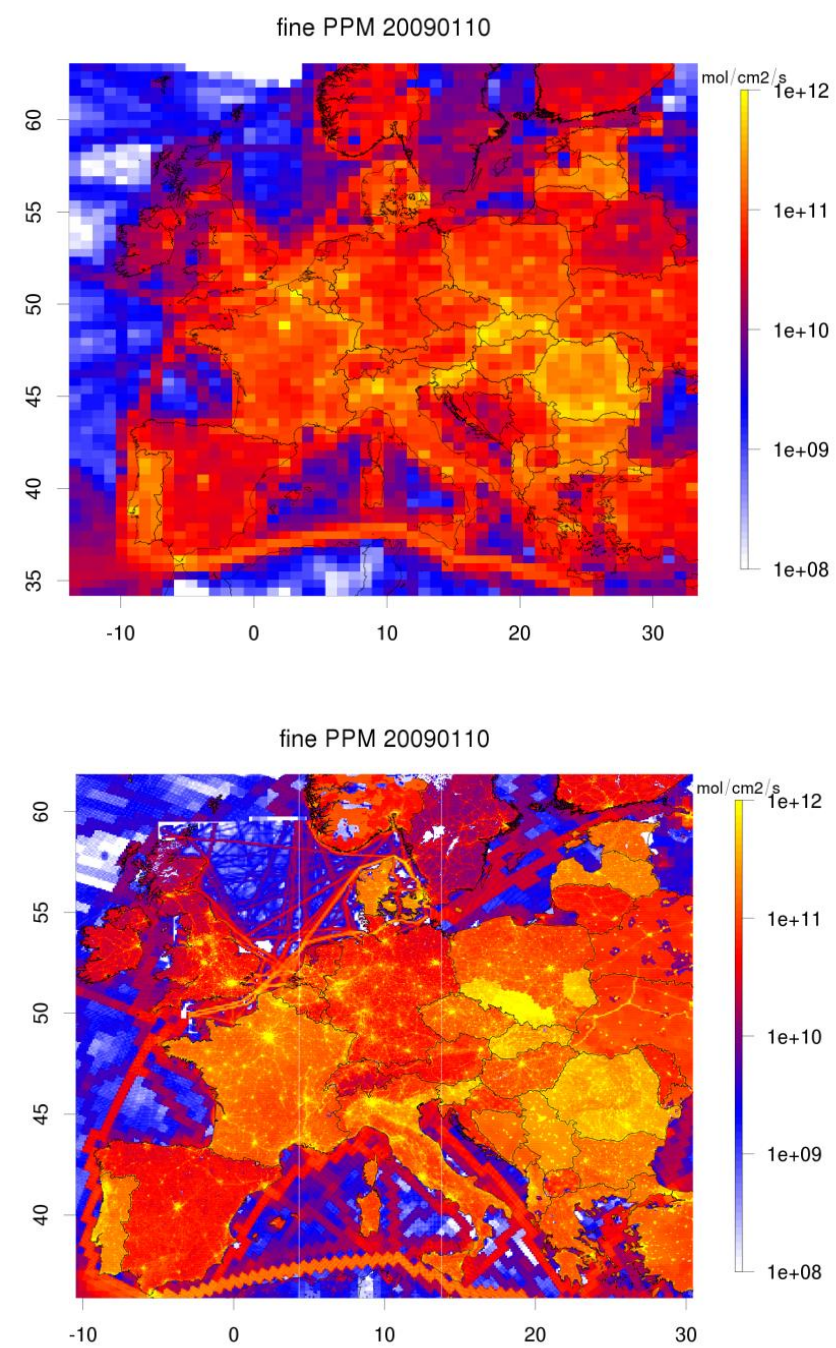

Fig. 1. Map of $\mathrm{NO}_{2}\left(\mu \mathrm{g} \mathrm{m}^{-3}\right)$ on 10 January 2009 at 16:00 UTC in the $57 \mathrm{~km}$ (top) and $2 \mathrm{~km}$ (bottom) resolution CHIMERE simulations.

at $0.125 \times 0.0625$ degree resolution (Kuenen et al., 2011) for SNAP activity sectors 3,7,8,9,10. Residential emissions (SNAP 2) were regridded according to population density maps and correlation coefficient between population and emissions derived from a French bottom-up inventory (Bessagnet et al., 2012). For SNAP sectors 1, 4, 5, 6 emissions are distributed over the artificial land use corresponding to EPER industries (eea.europa.eu/data-and-maps/data/ eper-the-european-pollutant-emission-register-4).

Annual maps of surface fluxes of emissions are then ultimately distributed along the year and in the vertical according to the Eurodelta protocol (Thunis et al., 2008). An additional correction is applied to take into account the impact of day-to-day temperature variations on the emission due to residential heating (degree-days concept) (Terrenoire et al., 2013). 
The above methodology is used to produce emission at the relevant resolution $(57,8$, or $2 \mathrm{~km})$ using the same coarselevel total fluxes (on the EMEP 0.5 degrees grid). A comparison of primary $\mathrm{PM}_{2.5}$ emission maps at 57 and $2 \mathrm{~km}$ is provided in Fig. 1. The areas where the coarse emission data set can be refined using appropriate proxies (population density, point sources) stand out clearly from the locations where such a downscaling is not possible (e.g. over sea surfaces). Note that the total emitted flux is identical in both cases.

\subsection{Observation data used for the validation}

The model results will be interpolated at the location of air quality monitoring stations reported in the AIRBASE repository (eea.europa.eu/themes/air/airbase) that includes Europewide hourly $\mathrm{NO}_{2}$ and daily $\mathrm{PM}_{10}$ and $\mathrm{PM}_{2.5}$ measurements from urban, suburban, and rural sites. The number of station per type and compound is given in Table 1.

\subsection{Computational setup and cost}

The simulations were parallelised on 2000 Intel Xeon processors at $2.7 \mathrm{GHz}$ with $64 \mathrm{G}$ memory by node. Tests were performed with up to 4000 processors with less satisfactory scaling properties. The total cost of the project was about $110000 \mathrm{~h}$ core, or $13 \mathrm{yr}$ on a single processor, but the wallclock time for $24 \mathrm{~h}$ of simulation was only $5 \mathrm{~h} 40$ (excluding the pre-processing). The storage of input/output files also constitutes an achievement with more than $2 \mathrm{~T}$ of data.

\section{Results}

\subsection{Qualitative presentation}

The maps in Fig. 2 illustrate the added value of increased resolution by showing snapshots of the simulations of nitrogen dioxide at about 57 and $2 \mathrm{~km}$ of resolution. A more dynamic view is accessible in the movie provided in the Supplement. While the coarse run captures well the main emission hotspots, local maxima over individual roads and isolated point sources (e.g. the oil rigs in the North Sea) are smeared out because of the numerical diffusion of the Eulerian model.

A more quantitative analysis of the added value of resolution will be provided in the following paragraphs, but the benefit of such a high-resolution simulation in raising awareness of the contribution of local sources in the accumulation of air pollution at the continental scale is worth mentioning. While discussions about the design of efficient air pollution mitigation policy measures often fall back to the choice of the most relevant geographical scale (local, national, continental), these high-resolution maps constitute a relevant reminder that in the field of atmospheric pollution as well, little brooks make great rivers.
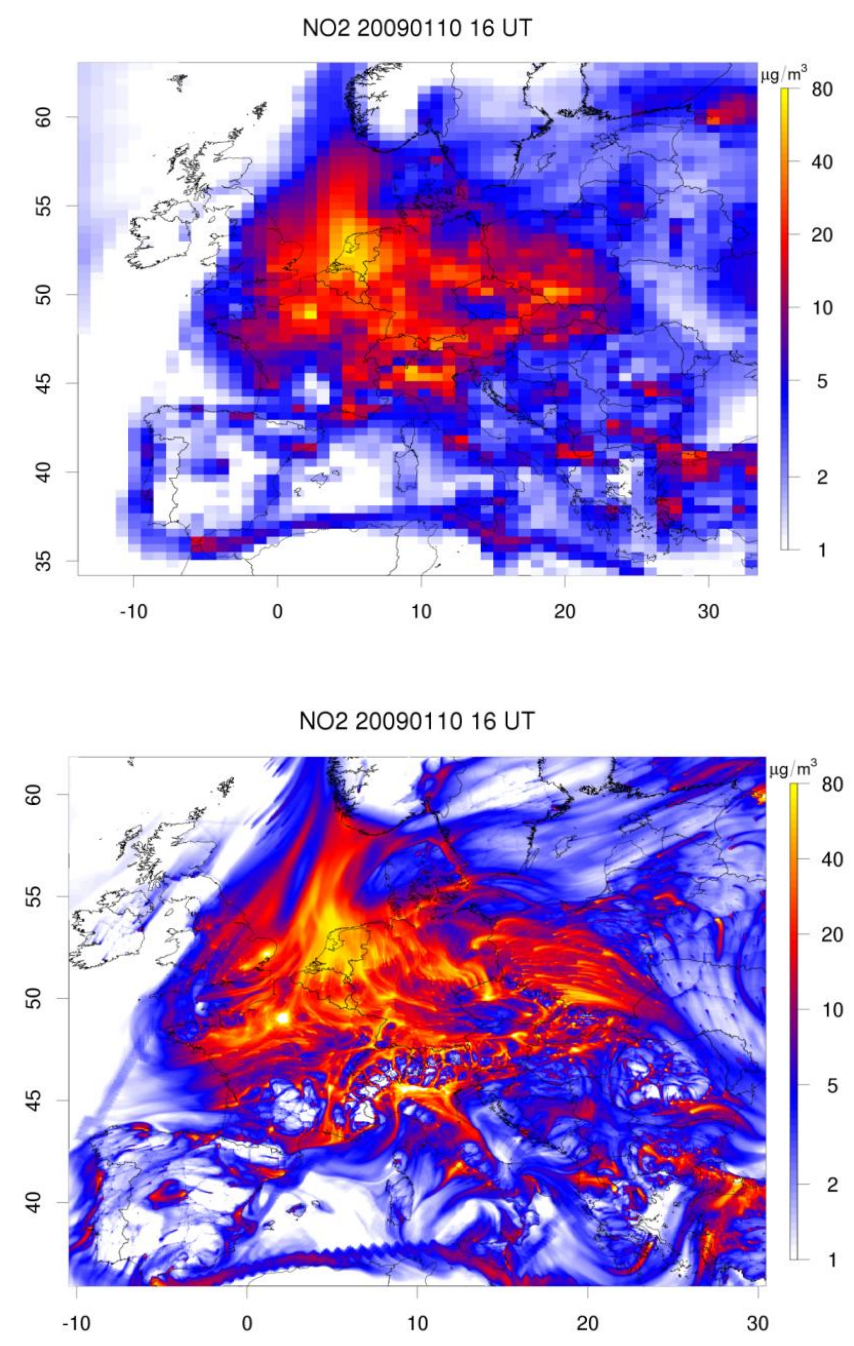

Fig. 2. Map of emissions of fine primary particulate matter (PPM) emissions (in molecule $\mathrm{cm}^{-2} \mathrm{~s}^{-1}$ ) over the day of 10 January 2009 in the $57 \mathrm{~km}$ (top) and $2 \mathrm{~km}$ (bottom) resolution domains.

\subsection{Evaluation against measurements}

A comparison with the observations allows discussing of the improvement in the performance of the model. An average of time series of $\mathrm{NO}_{2}$ at all urban, suburban and rural monitoring stations in the Paris area (geographical box $47^{\circ} \mathrm{N}, 50^{\circ} \mathrm{N}$, $1.5^{\circ} \mathrm{E}, 3.5^{\circ} \mathrm{E}$ ) is given in Fig. 3. The upper panel (urban stations) illustrates well the improvement brought about by the increased resolution to capture high pollution levels in urban areas. Whereas the coarse simulation is only able to reproduce the diurnal cycle and the daily variability with an important average bias, moving to a $8 \mathrm{~km}$ resolution improves the average level and daytime values, while night-time and morning peaks are further improved when moving to a $2 \mathrm{~km}$ resolution. The differences between the $8 \mathrm{~km}$ and $2 \mathrm{~km}$ setups almost vanish when focusing on suburban stations (second panel of Fig. 3), and looking further at rural stations (low 
Table 1. Model performances (root mean square error, mean fractional bias and average spatial correlation) of each configuration over the whole modelling domain for three types of background stations (urban, suburban, rural) between 9 and 16 January 2009. The average of observations over the whole period is also given as well as the number of exceedances (Exceed.) of regulatory thresholds: $200 \mu \mathrm{g} \mathrm{m}^{-3}$ for hourly $\mathrm{NO}_{2}$ and $50 \mu \mathrm{g} \mathrm{m}^{-3}$ for daily $\mathrm{PM}_{10}$.

\begin{tabular}{|c|c|c|c|c|c|c|c|c|c|c|c|c|c|c|c|c|}
\hline \multirow[b]{2}{*}{ Pollutant } & \multirow[b]{2}{*}{$\begin{array}{l}\text { Station } \\
\text { type }\end{array}$} & \multirow[b]{2}{*}{$\begin{array}{l}\text { Number } \\
\text { of sites }\end{array}$} & \multirow[b]{2}{*}{$\begin{array}{l}\text { Average } \\
\text { observed }\end{array}$} & \multirow[b]{2}{*}{ Exceed. } & \multicolumn{4}{|c|}{$57 \mathrm{~km}$} & \multicolumn{4}{|c|}{$8 \mathrm{~km}$} & \multicolumn{4}{|c|}{$2 \mathrm{~km}$} \\
\hline & & & & & $\begin{array}{r}\text { RMSE } \\
\left(\mu \mathrm{g} \mathrm{m}^{-3}\right)\end{array}$ & Corr. & MFB & Exceed. & $\begin{array}{r}\text { RMSE } \\
\left(\mu \mathrm{g} \mathrm{m}^{-3}\right)\end{array}$ & Corr. & MFB & Exceed. & $\begin{array}{r}\text { RMSE } \\
\left(\mu \mathrm{g} \mathrm{m}^{-3}\right)\end{array}$ & Corr. & MFB & Exceed. \\
\hline \multirow[t]{3}{*}{$\mathrm{NO}_{2}$} & Urban & 721 & 47.3 & 223 & 33.00 & 0.68 & -1.04 & 0 & 24.37 & 0.66 & -0.59 & 130 & 21.51 & 0.64 & -0.38 & 317 \\
\hline & Suburban & 380 & 45.9 & 116 & 30.19 & 0.68 & -0.93 & 0 & 22.75 & 0.67 & -0.52 & 69 & 21.57 & 0.66 & -0.42 & 70 \\
\hline & Rural & 345 & 25.4 & 0 & 16.94 & 0.54 & -0.42 & 0 & 14.72 & 0.59 & -0.29 & 3 & 14.81 & 0.61 & -0.33 & 5 \\
\hline \multirow[t]{3}{*}{$\mathrm{PM}_{10}$} & Urban & 633 & 66.0 & 2648 & 48.70 & 0.32 & -0.81 & 209 & 43.62 & 0.31 & -0.59 & 751 & 42.29 & 0.29 & -0.44 & 1238 \\
\hline & Suburban & 293 & 58.5 & 1104 & 38.36 & 0.48 & -0.67 & 133 & 34.08 & 0.49 & -0.48 & 343 & 32.47 & 0.49 & -0.38 & 476 \\
\hline & Rural & 221 & 38.0 & 462 & 23.47 & 0.59 & -0.28 & 46 & 21.59 & 0.65 & -0.23 & 84 & 20.37 & 0.64 & -0.16 & 131 \\
\hline \multirow[t]{3}{*}{$\mathrm{PM}_{2.5}$} & Urban & 161 & 44.6 & & 27.51 & 0.62 & -0.58 & & 24.69 & 0.57 & -0.39 & & 22.78 & 0.58 & -0.22 & \\
\hline & Suburban & 68 & 43.7 & & 26.68 & 0.67 & -0.59 & & 23.53 & 0.58 & -0.37 & & 22.32 & 0.56 & -0.27 & \\
\hline & Rural & 70 & 27.2 & & 16.19 & 0.68 & -0.12 & & 14.70 & 0.77 & -0.02 & & 14.05 & 0.76 & 0.07 & \\
\hline
\end{tabular}

panel of Fig. 3), we find that the three model setups give very similar results.

The performances of the model are further quantified in Table 1 that synthesizes a few key statistical metrics: the root mean square error (RMSE) and the mean fractional bias (MFB) between the model and observations (based on daily values) averaged across the Europe-wide AIRBASE network as well as daily spatial correlation coefficients throughout Europe averaged over the whole period. For the spatial correlation, we used Pearson's definition: the covariance between $X$ and $Y$ divided by the product of the standard deviation of $X$ times that of $Y$, where $X$ is the set of observed valued over Europe at a given time and $Y$ the corresponding modelled set. The MFB is defined as the average of normalised differences between model and observation (i.e. model minus observation divided by the average between model and observation). It ranges between -2 and 2 and has an ideal value of 0 . The MFB provides additional information compared with RMSE by providing the sign of the difference on a normalised basis.

We find that increasing the resolution improves significantly the root mean square error and mean fractional bias, especially at urban sites. The difference between the RMSE and MFB at urban, suburban and rural stations decreases with the resolution, showing that we resolve better spatial gradients. This feature is more sensitive for $\mathrm{NO}_{2}$ than for $\mathrm{PM}_{10}$ or $\mathrm{PM}_{2.5}$ because of the lower spatial variability of the latter, yielding this higher sensitivity of $\mathrm{NO}_{2}$ often reported at urban sites.

Table 1 somehow questions the relevance of very highresolution simulations since the bulk of the improvement is achieved at $8 \mathrm{~km}$ resolution, for which the RMSE of daily mean $\mathrm{NO}_{2}$ averaged over the whole monitoring network is $24 \%$ (10\% for $\mathrm{PM}_{10}$ ) lower than the $57 \mathrm{~km}$ simulation, and the $2 \mathrm{~km}$ resolution adds only another $6 \%$ ( $4 \%$ for $\left.\mathrm{PM}_{10}\right)$ reduction to achieve an average RMSE $30 \%$ (14\% for $\mathrm{PM}_{10}$ ) lower than the coarsest configuration.

In addition, the improvement in the spatial correlation is only seen at rural sites (and suburban sites for $\mathrm{PM}_{10}$ ).
Discussing spatial correlation clustered by station type is however slightly unfavourable given that it ignores the improvement in spatial gradient between urban/suburban/rural areas. The spatial correlation for $\mathrm{NO}_{2}$ over the whole network improves from 0.63 to 0.67 and 0.67 in the $57 \mathrm{~km}, 8 \mathrm{~km}$, and $2 \mathrm{~km}$ setups, respectively.

Nevertheless one could have expected that the improvement would have been even larger. These figures illustrate the need to investigate further more sophisticated emission top-down downscaling algorithms, and to account for smallscale dynamical meteorological features (such as urban processes).

\subsection{Exceedances}

Table 1 only addresses average biases and similar limited added values of increased resolution were reported before as far as mean or fractional biases are concerned (Fountoukis et al., 2013; Tesche et al., 2006). On the contrary, the performances in terms of exceedances (which are notably challenging to capture with numerical models because of thresholding effects even if they carry a high regulatory relevance in the European air quality legislation; EC, 2008) are improved at very high resolution. For $\mathrm{PM}_{10}$, the daily limit value of $50 \mu \mathrm{g} \mathrm{m}^{-3}$ was exceeded 4214 times throughout the European monitoring network between 9 and 16 January 2009 (1147 monitoring stations and 8 days, i.e. almost $50 \%$ of observations on average). Using a $57 \mathrm{~km}$ resolution, only 388 exceedances (or about $10 \%$ ) are captured by the CTM, but the increased resolution improves this number, with $28 \%$ and $44 \%$ of the exceedances captured by the model at $8 \mathrm{~km}$ and $2 \mathrm{~km}$ of resolution, respectively.

Similarly, no exceedances of the $200 \mu \mathrm{g} \mathrm{m}^{-3}$ threshold for hourly $\mathrm{NO}_{2}$ values were captured with the $57 \mathrm{~km}$ resolution setup, while this threshold had been exceeded 339 times over the period. Moving to higher resolution allows capturing of such events, to the extent of producing $15 \%$ too many exceedances at $2 \mathrm{~km}$ resolution. 

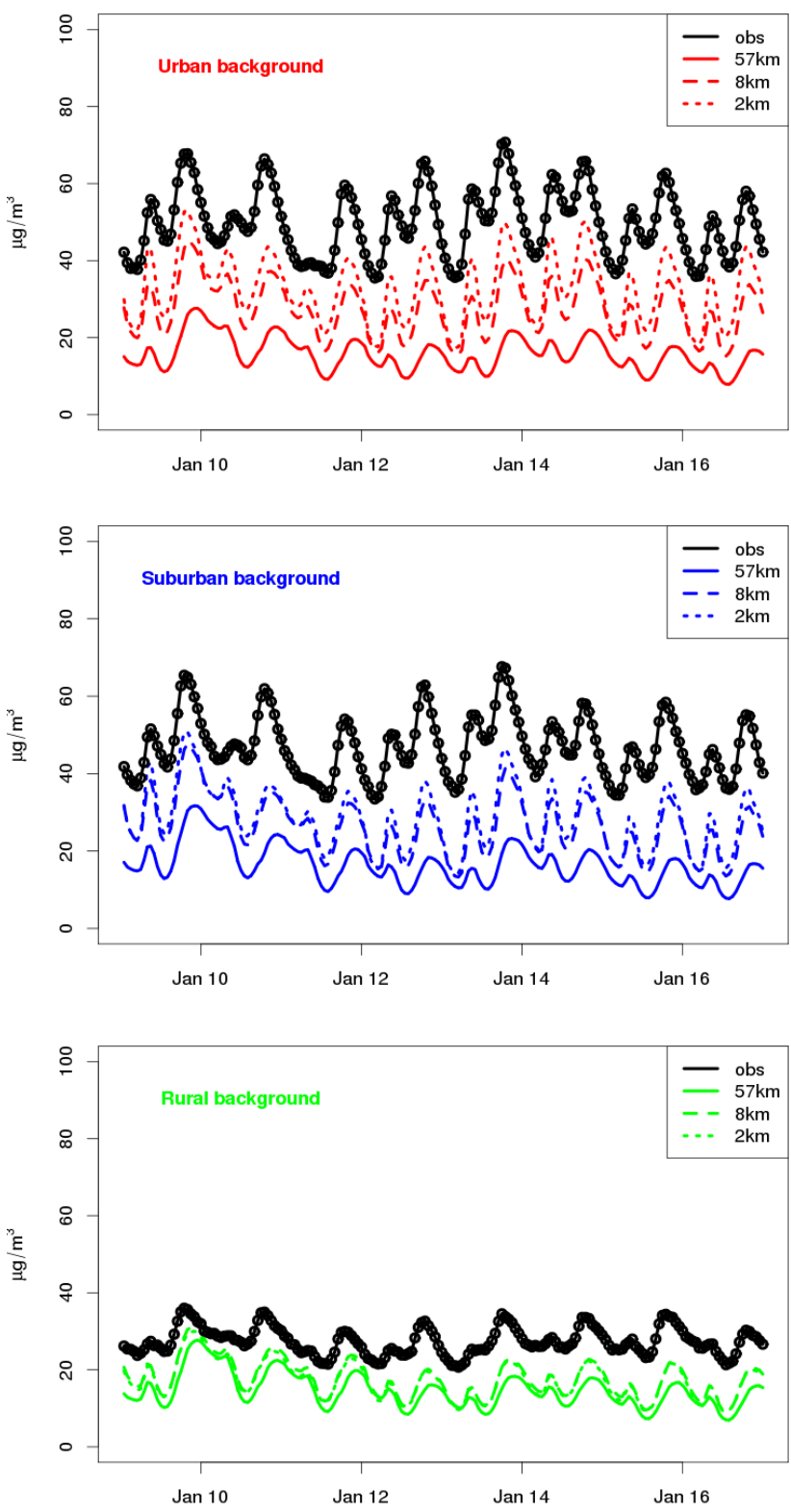

Fig. 3. Average time series of hourly $\mathrm{NO}_{2}\left(\mu \mathrm{g} \mathrm{m}^{-3}\right)$ observed at, from the top to the bottom, urban, suburban and rural background monitoring stations in the Paris area (black) and interpolated in the CHIMERE model simulations at the $57 \mathrm{~km}$ (solid), $8 \mathrm{~km}$ (dashed), and $2 \mathrm{~km}$ (dotted) resolutions.

\subsection{Budget and fluxes}

The non-linearity of the atmospheric chemistry system yields a slight sensitivity to the resolution of the total mass of modelled particulate matter aggregated over Western Europe $\left(10^{\circ} \mathrm{W}, 30^{\circ} \mathrm{E}, 36^{\circ} \mathrm{N}, 60^{\circ} \mathrm{N}\right)$. The average $\mathrm{PM}_{10}$ load is 17.4 , 19.5 and $20.7 \mu \mathrm{g} \mathrm{m}^{-3}$, for the 57,8 , and $2 \mathrm{~km}$ resolution simulations respectively, while the corresponding figures for $\mathrm{NO}_{2}$ are $10.2,13.8$, and $14.4 \mu \mathrm{g} \mathrm{m}^{-3}$.
The increased resolution thus also has an impact on the net fluxes. Net horizontal fluxes at the grid points along a given vertical boundary are computed by summing in time the hourly product of concentration of a pollutant times normal wind. The cumulated flux is then taken by aggregating grid-point fluxes over a meridional or zonal boundary, or even over a closed polygon. All fluxes are computed up to the top of the domain $(500 \mathrm{hPa})$ and vertical fluxes are ignored.

We find that ignoring fine plumes in the coarse simulation leads to an underestimation of long-range transport. In particular, the eastward flux of $\mathrm{PM}_{2.5}$ built up over Western Europe during the first half of the event is underestimated by $15 \%$ in the $57 \mathrm{~km}$ simulation compared with the $2 \mathrm{~km}$ simulation. When focusing on individual cities, we found that the net export of $\mathrm{PM}_{2.5}$ in the immediate vicinity of the Paris area $\left(1.4375^{\circ} \mathrm{E}, 3.1875^{\circ} \mathrm{E}, 47.96875^{\circ} \mathrm{N}, 49.71875^{\circ} \mathrm{N}\right)$ is $26 \%$ (resp. $11 \%$ ) lower in the $57 \mathrm{~km}$ (resp. $8 \mathrm{~km}$ ) resolution simulation compared to the $2 \mathrm{~km}$ run. For $\mathrm{NO}_{2}$, these figures are $32 \%$ (resp. $-2 \%$ ) for the $57 \mathrm{~km}$ and $8 \mathrm{~km}$ resolutions. It should be emphasised that surface emission fluxes are identical in all simulations. The differences obtained for the export flux of $\mathrm{NO}_{2}$ are thus partly induced by the difference in the spatialisation of these emissions that are smeared out in the coarse simulation over the boundaries of the Paris area defined above. The similarity of export flux for $\mathrm{NO}_{2}$ in the $2 \mathrm{~km}$ and $8 \mathrm{~km}$ simulations shows that the intermediate $8 \mathrm{~km}$ setup is somewhat satisfactory to capture urban $\mathrm{NO}_{2}$ patterns, considering available emission data. On the contrary, we find an additional improvement at $2 \mathrm{~km}$ for $\mathrm{PM}_{2.5}$ attributed to the non-linear chemical formation of secondary particles.

\subsection{Exposure}

The sensitivity is even larger when it comes to exposure modelling. Because highly populated areas are correlated with emissions hotspots, the horizontal gradients matter when weighting pollution load by population density. Here we find that on average over the 9-day period, in the highresolution simulation 87.9 million people (out of 588 million inhabitants included in the modelling domain) were exposed to daily concentrations exceeding the daily limit value of $50 \mathrm{\mu g} \mathrm{m}^{-3}$ for $\mathrm{PM}_{10}$ according to the EU Directive on ambient air quality (2008/50/EC). Using a $57 \mathrm{~km}$ grid, the same estimate would be 18.2 million people, i.e. almost a factor 5 underestimation if the additional increment of pollution in urban areas is ignored.

\section{Conclusions}

By producing the first continental-scale $2 \mathrm{~km}$ resolution air quality simulation performed on a $2000 \mathrm{CPU}$ computer, we introduced the first steps of atmospheric chemistry modelling 
in the era of very high performance computing. This frontier simulation is two orders of magnitude above current practices in terms of computational demand.

Besides the technical challenge, which demonstrated the robustness of the CHIMERE air quality model, we discuss the added value in terms of air pollution modelling and decision support. The comparison with in situ observations shows that model biases are significantly improved despite some spurious added spatial variability attributed to the coarse resolution of the meteorological fields shortcomings in the emission downscaling process. The high-resolution emission inventory used here relies on a top-down approach that uses European-wide proxies for the spatial distribution. The quality of the emission spatialisation would be greatly improved by using national emission reported at finer resolution than current standards (e.g. $10 \mathrm{~km}$ instead of $50 \mathrm{~km}$ ) instead of coarse high-level proxies.

The increased spatial resolution is clearly beneficial for the detection of exceedances, the quantification of transport fluxes and exposure modelling resulting from the nonlinearity of the atmospheric system. We exhibit dynamic air pollution patterns that highlight the contribution of the city plumes to the background air pollution levels. Reciprocally, the contribution of long-range transport to exceedances of regulatory threshold values for $\mathrm{PM}_{10}$ and $\mathrm{NO}_{2}$ in urban areas is better assessed as a result of reduced diffusion. The underestimation in terms of net export flux of trace species is of the order of $25 \%$ for a city like Paris, which raises important concerns in studies focusing on impacts on remote areas with large-scale coarse models. Lastly, up to a factor 5 underestimation of the fraction of population exposed to detrimental levels of pollution can be derived with a simulation at coarse resolution if subgrid scale correction such as urban increments (Amann et al., 2011; Denby et al., 2011) are ignored to cope with the lack of an explicit high-resolution model.

We conclude that significant improvement can be sought after by refining the geographical mesh of atmospheric chemistry models. Better results can be achieved thanks to an improved representation of the contribution of local sources in the build-up of continental-scale events, in the net transport fluxes and in the aggregated population exposure to detrimental air pollution levels. This experiment opens new perspectives for decision making. In Europe, considering the achievements after two decades of efforts to reduce air pollutant emissions, the challenge is now to find the optimal tradeoff between national and local air quality management strategies. While the first approach is based on sectoral strategies and energy policies, the latter builds upon new alternatives such as urban development. The strategies, the decision pathways and the involvement of individual citizens differ, and a compromise based on cost and efficiency must be found. We illustrated how high-performance computing in atmospheric science can contribute to this aim by improving modelling of exposure, exceedance, and export of pollution. Specifically, our finding on the underestimation of about $25 \%$ for the export fluxes of fine particulate matter of a city like Paris in $57 \mathrm{~km}$ simulation compared to the $2 \mathrm{~km}$ setup provides a new insight into the relative contribution of individual cities to the European burden, raising new questions with regards to the appropriate level of action for air pollution mitigation, although further developments are still needed to secure the results for routine policy use.

\section{Supplementary material related to this article is available online at http://www.geosci-model-dev.net/7/ 203/2014/gmd-7-203-2014-supplement.zip.}

Acknowledgements. The high-performance computing facility and staff at CCRT/CEA is gratefully acknowledged. EEA granted access to the AIRBASE monitoring data and ECMWF to meteorological forcing. European funding also benefited from this initiative through the MACC-II (grant agreement no. 283576) project of the European Union's Seventh Framework Programme (FP7/20072013) and the EC4MACS project of the Life Programme of the European Commission (LIFE06 ENV/AT/PREP/06).

Edited by: A. Lauer

\section{References}

Amann, M., Bertok, I., Borken-Kleefeld, J., Cofala, J., Heyes, C., Höglund-Isaksson, L., Klimont, Z., Nguyen, B., Posch, M., Rafaj, P., Sandler, R., Schöpp, W., Wagner, F., and Winiwarter, W.: Cost-effective control of air quality and greenhouse gases in Europe: Modeling and policy applications, Environ. Model. Softw., 26, 1489-1501, 2011.

Bessagnet, B., Menut, L., Curci, G., Hodzic, A., Guillaume, B., Liousse, C., Moukhtar, S., Pun, B., Seigneur, C., and Schulz, M.: Regional modeling of carbonaceous aerosols over Europe - focus on secondary organic aerosols, J. Atmos. Chem., 61, 175-202, 2008.

Bessagnet, B., Terrenoire, E., Tognet, F., Rouïl, L., Colette, A., Letinois, L., and Malherbe, L.: EC4MACS Modelling Methodology: The CHIMERE Atmospheric Model, INERIS, 2012.

Chiappini, L.: Métrologie des particules $\mathrm{PM}_{10}$ et $\mathrm{PM}_{2.5}$ - Caractérisation Chimique des Particules - Veille sur les études de sources, Ministère de l'Ecologie, de l'Energie, du Développement durable et de la Mer, Paris, 49 pp., 2009.

Colette, A., Granier, C., Hodnebrog, Ø., Jakobs, H., Maurizi, A., Nyiri, A., Bessagnet, B., D’Angiola, A., D’Isidoro, M., Gauss, M., Meleux, F., Memmesheimer, M., Mieville, A., Rouïl, L., Russo, F., Solberg, S., Stordal, F., and Tampieri, F.: Air quality trends in Europe over the past decade: a first multi-model assessment, Atmos. Chem. Phys., 11, 11657-11678, doi:10.5194/acp11-11657-2011, 2011.

Cuvelier, C., Thunis, P., Vautard, R., Amann, M., Bessagnet, B., Bedogni, M., Berkowicz, R., Brandt, J., Brocheton, F., Builtjes, P., Carnavale, C., Coppalle, A., Denby, B., Douros, J., Graf, A., Hellmuth, O., Hodzic, A., Honoré, C., Jonson, J., Kerschbaumer, A., de Leeuw, F., Minguzzi, E., Moussiopoulos, N., Pertot, C., Peuch, V. H., Pirovano, G., Rouil, L., Sauter, F., Schaap, M., 
Stern, R., Tarrason, L., Vignati, E., Volta, M., White, L., Wind, P., and Zuber, A.: CityDelta: A model intercomparison study to explore the impact of emission reductions in European cities in 2010, Atmos. Environ., 41, 189-207, 2007.

Denby, B., Cassiani, M., de Smet, P., de Leeuw, F., and Horalek, J.: Sub-grid variability and its impact on European wide air quality exposure assessment, Atmos. Environ., 45, 4220-4229, 2011.

DWD: Annual Bulletin on the Climate in WMO Region VI: Europe and Middle East, 2009, World Meteorological Organisation, Offenbach am Main, 2010

EC: Directive 2008/50/EC of the European Parliament and of the Council of 21 May 2008 on ambient air quality and cleaner air for Europe, European Commission, Brussels, 2008.

Eder, B., Kang, D., Mathur, R., Pleim, J., Yu, S., Otte, T., and Pouliot, G.: A performance evaluation of the National Air Quality Forecast Capability for the summer of 2007, Atmos. Environ., 43, 2312-2320, 2009.

Favez, O., El Haddad, I., Piot, C., Boréave, A., Abidi, E., Marchand, N., Jaffrezo, J.-L., Besombes, J.-L., Personnaz, M.-B., Sciare, J., Wortham, H., George, C., and D'Anna, B.: Inter-comparison of source apportionment models for the estimation of wood burning aerosols during wintertime in an Alpine city (Grenoble, France), Atmos. Chem. Phys., 10, 5295-5314, doi:10.5194/acp-10-52952010, 2010.

Folberth, G. A., Hauglustaine, D. A., Lathière, J., and Brocheton, F.: Interactive chemistry in the Laboratoire de Météorologie Dynamique general circulation model: model description and impact analysis of biogenic hydrocarbons on tropospheric chemistry, Atmos. Chem. Phys., 6, 2273-2319, doi:10.5194/acp-62273-2006, 2006.

Fountoukis, C., Koraj, D., Denier van der Gon, H. A. C., Charalampidis, P. E., Pilinis, C., and Pandis, S. N.: Impact of grid resolution on the predicted fine PM by a regional 3-D chemical transport model, Atmospheric Environment, 68, 24-32, 2013.

Galmarini, S., Rao, S. T., and Steyn, D. G.: Preface, Atmos. Environ., 53, 1-3, 2012.

Hauglustaine, D. A., Hourdin, F., Jourdain, L., Filiberti, M. A., Walters, S., Lamarque, J. F., and Holland, E. A.: Interactive chemistry in the Laboratoire de Météorologie Dynamique general circulation model: Description and background tropospheric chemistry evaluation, J. Geophys. Res., 109, D04314, doi:10.1029/2003JD003957, 2004.

Kuenen, J., Denier van der Gon, H., Visschedijk, A., van der Burgh, H., and van Gijlswijk, R.: MACC European emission inventory 2003-2007, TNO, 2011.

MEEDDM: Bilan de la qualité de l'air en France en 2009 et des principales tendances observées au cours de la période 20002009, Ministère de l'Écologie, de l'Énergie, du Développement durable et de la Mer, Paris, 2010.

Menut, L., Goussebaile, A., Bessagnet, B., Khvorostiyanov, D., and Ung, A.: Impact of realistic hourly emissions profiles on modelled air pollutants concentrations, Atmos. Environ., 233, doi:10.1016/j.atmosenv.2011.11.057, 2012.
Menut, L., Bessagnet, B., Khvorostyanov, D., Beekmann, M., Blond, N., Colette, A., Coll, I., Curci, G., Foret, G., Hodzic, A., Mailler, S., Meleux, F., Monge, J.-L., Pison, I., Siour, G., Turquety, S., Valari, M., Vautard, R., and Vivanco, M. G.: CHIMERE 2013: a model for regional atmospheric composition modelling, Geosci. Model Dev., 6, 981-1028, doi:10.5194/gmd6-981-2013, 2013.

Terrenoire, E., Bessagnet, B., Rouïl, L., Tognet, F., Pirovano, G., Létinois, L., Colette, A., Thunis, P., Amann, M., and Menut, L.: High resolution air quality simulation over Europe with the chemistry transport model CHIMERE, Geosci. Model Dev. Discuss., 6, 4137-4187, doi:10.5194/gmdd-6-4137-2013, 2013.

Tesche, T. W., Morris, R., Tonnesen, G., McNally, D., Boylan, J., and Brewer, P.: CMAQ/CAMx annual 2002 performance evaluation over the eastern US, Atmos. Environ., 40, 4906-4919, 2006.

Thunis, P., Cuvelier, C., Roberts, P., White, L., Post, L., Tarrason, L., Tsyro, S., Stern, R., Kerschbaumer, A., Rouil, L., Bessagnet, B., Builtjes, J., Schaap, M., Boersen, G., and Bergstroem, R.: Evaluation of a Sectoral Approach to Integrated Assessment Modelling including the Mediterranean Sea, JRC, Ispra, Italy, 2008.

van Loon, M., Vautard, R., Schaap, M., Bergström, R., Bessagnet, B., Brandt, J., Builtjes, P. J. H., Christensen, J. H., Cuvelier, C., Graff, A., Jonson, J. E., Krol, M., Langner, J., Roberts, P., Rouil, L., Stern, R., Tarrasón, L., Thunis, P., Vignati, E., White, L., and Wind, P.: Evaluation of long-term ozone simulations from seven regional air quality models and their ensemble, Atmos. Environ., 41, 2083-2097, 2007.

Vautard, R., Schaap, M., Bergstrom, R., Bessagnet, B., Brandt, J., Builtjes, P. J. H., Christensen, J. H., Cuvelier, C., Foltescu, V., Graff, A., Kerschbaumer, A., Krol, M., Roberts, P., Rouïl, L., Stern, R., Tarrason, L., Thunis, P., Vignati, E., and Wind, P.: Skill and uncertainty of a regional air quality model ensemble, Atmos. Environ., 43, 4822-4832, 2009.

Vestreng, V., Myhre, G., Fagerli, H., Reis, S., and Tarrasón, L.: Twenty-five years of continuous sulphur dioxide emission reduction in Europe, Atmos. Chem. Phys., 7, 3663-3681, doi:10.5194/acp-7-3663-2007, 2007.

Zhang, Y., Bocquet, M., Mallet, V., Seigneur, C., and Baklanov, A.: Real-time air quality forecasting, part I: History, techniques, and current status, Atmos. Environ., 60, 632-655, 2012.

Zyryanov, D., Foret, G., Eremenko, M., Beekmann, M., Cammas, J.-P., D’Isidoro, M., Elbern, H., Flemming, J., Friese, E., Kioutsioutkis, I., Maurizi, A., Melas, D., Meleux, F., Menut, L., Moinat, P., Peuch, V.-H., Poupkou, A., Razinger, M., Schultz, M., Stein, O., Suttie, A. M., Valdebenito, A., Zerefos, C., Dufour, G., Bergametti, G., and Flaud, J.-M.: 3-D evaluation of tropospheric ozone simulations by an ensemble of regional Chemistry Transport Model, Atmos. Chem. Phys., 12, 3219-3240, doi:10.5194/acp-12-3219-2012, 2012. 